Results All procedures had technical success with no immediate complication related to OTSC application. Patients were followed up for every month with a mean duration of follow up 10.2 months. One patient with bronchoesophageal fistula had the development of another fistulous opening above the site of OTSC placement, which was successfully closed with another OTSC. One patient had superficial esophageal wall ulcer opposite the OTSC, but it healed spontaneously.

Conclusions OTSC provided safe and successful closure in a number of settings such as the closure of fistula, perforation, dehiscence.

\section{IDDF2018-ABS-0016 REMOVABLE SELF-EXPANDING METAL STENTS INSERTION FOR THE TREATMENT OF PERFORATIONS AND POSTOPERATIVE LEAKS OF THE OESOPHAGUS}

Mukesh Nasa*, Narendra Choudhary, Rajesh Puri. Medanta-The Medicity, India

\subsection{6/gutjnl-2018-IDDFabstracts.65}

Background Esophageal rupture, spontaneous or iatrogenic, is associated with significant morbidity and mortality. The current study aims at highlighting the various clinical scenarios, where esophageal fully covered self-expanding removable metal stents (FCSEMS) can be used in esophageal rupture.

Methods In patients who underwent insertion of FCSEMS between January 2013 and June 2014, all data regarding demographics, indications, insertion, removal, and outcomes were studied retrospectively (table 1). Seven patients underwent the placement of esophageal covered SEMS. Two patients had Boerhaave syndrome (figure 1), two had leak following the repair of an aortic aneurysm, one had extensive esophageal injury following transesophageal echocardiography, one had carcinoma oesophagus with tracheaesophageal fistula, and one had dehiscence of esophagogastric anastomosis.

Results Seven patients underwent the placement of esophageal covered SEMS. Two patients had Boerhaave syndrome, two had leak following the repair of an aortic aneurysm, one had extensive esophageal injury following transesophageal echocardiography, one had carcinoma oesophagus with tracheaesophageal fistula, and one had dehiscence of esophagogastric anastomosis. Stent insertion was successful in all the patients; one had stent migration which was managed endoscopically. Two patients died due to underlying illness; the rest had successful removal of stents after 8-10 weeks and good outcomes.

Conclusions Esophageal FCSEMS placement is safe and effective modality in the management of patients with esophageal rupture.

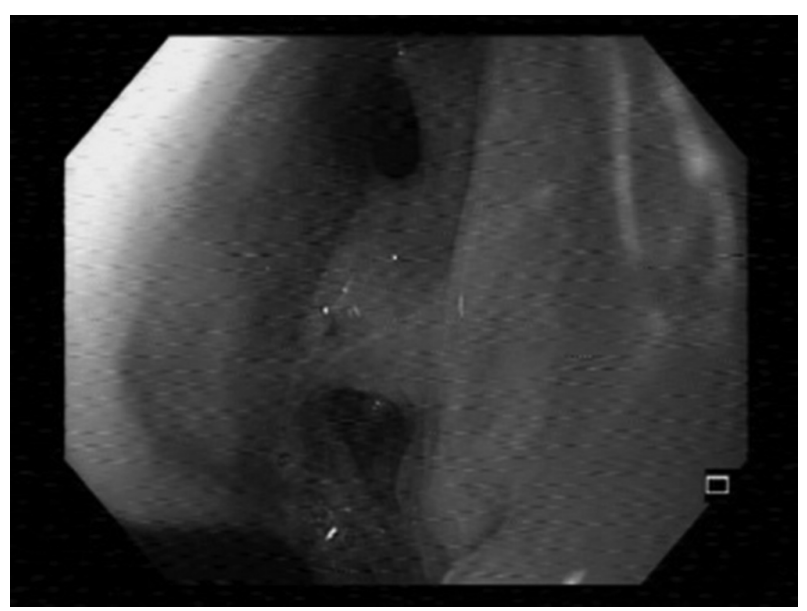

Abstract IDDF2018-ABS-0016 Figure 1

\section{IDDF2018-ABS-0017 SPLENOADRENAL SHUNT FOR NONCIRRHOTIC PORTAL HYPERTENSION}

Kalayarasan Raja*. JIPMER, India

\subsection{6/gutjnl-2018-IDDFabstracts.66}

Background Portosystemic shunt surgery is an established treatment option for preventing variceal rebleeding in patients with noncirrhotic portal hypertension $(\mathrm{NCPH})$. The proximal splenorenal shunt is a widely performed procedure in these patients. In this study, the use of adrenal vein as an alternative conduit has been investigated.

Methods A retrospective analysis of patients with NCPH who underwent proximal splenoadrenal and splenorenal shunt between 2011 and 2015 was performed. Demographic findings, aetiology of portal hypertension, clinical presentation, haematological parameters, liver function test, intraoperative findings, postoperative morbidity, and shunt patency were studied and compared between the two groups. All patients were followed up for a minimum of 12 months with Doppler

\begin{tabular}{|c|c|c|c|c|c|c|c|}
\hline Patient & $\begin{array}{l}\text { Age/ } \\
\text { Gender }\end{array}$ & History & Indication of stenting & $\begin{array}{l}\text { Interval between diagnosis of leak to placement } \\
\text { of SEMS(days) }\end{array}$ & $\begin{array}{l}\text { Length of stent } \\
\qquad(\mathrm{mm})\end{array}$ & $\begin{array}{l}\text { Removal done after } \\
\text { (weeks) }\end{array}$ & Outcome \\
\hline 1. & $44 / \mathrm{M}$ & Spontaneous distal eso rupture & Boerhaave syn & 2 & 120 & 8 & Recovery \\
\hline 2. & $68 / \mathrm{M}$ & Haemetemesis following TEE & $\begin{array}{l}\text { Mid and lower } \\
\text { esophageal tear }\end{array}$ & 1 & 120 (two stents) & 10 & Recovery \\
\hline 3. & $48 / \mathrm{M}$ & Thoracic aorta aneurysm repair & Mid-esophageal leak & 8 & 120 & - & Expired \\
\hline 4. & $60 / F$ & Spontaneous distal eso rupture & Boerhaave syn & 1 & 120 & 10 & Recovery \\
\hline 5. & $42 / \mathrm{M}$ & $\begin{array}{l}\text { Total gastrectomy with esophago- } \\
\text { jejunostomy }\end{array}$ & Anastomotic leak & 40 & 120 & - & Expired \\
\hline 6. & $44 / M$ & Thoracic aorta aneurysm repair & Esophageal leak & 2 & 120 & 8 & Recovery \\
\hline 7. & $57 / M$ & $\begin{array}{c}\text { Carcinoma oesophagus with esophago- } \\
\text { pleural fistula }\end{array}$ & Esophago-pleural fistula & 7 & 120 & 10 & Recovery \\
\hline
\end{tabular}

